\title{
Identifying Stabilising Effects on Survey Based Life Satisfaction Using Quasi-maximum Likelihood Estimation
}

\author{
Johannes Klement ${ }^{1}$ (C)
}

Accepted: 28 February 2021 / Published online: 31 March 2021

(c) The Author(s) 2021

\begin{abstract}
To which extent do happiness correlates contribute to the stability of life satisfaction? Which method is appropriate to provide a conclusive answer to this question? Based on life satisfaction data of the German SOEP, we show that by Negative Binomial quasi-maximum likelihood estimation statements can be made as to how far correlates of happiness contribute to the stabilisation of life satisfaction. The results show that happiness correlates which are generally associated with a positive change in life satisfaction, also stabilise life satisfaction and destabilise dissatisfaction with life. In such as they lower the probability of leaving positive states of life satisfaction and increase the probability of leaving dissatisfied states. This in particular applies to regular exercise, volunteering and living in a marriage. We further conclude that both patterns in response behaviour and the quality of the measurement instrument, the life satisfaction scale, have a significant effect on the variation and stability of reported life satisfaction.
\end{abstract}

Keywords Stabilisation of life satisfaction - Adaptation · Quasi-maximum likelihood estimate $\cdot$ German socio-economic panel

\section{Introduction}

Providing answers to the question as to which extent our living conditions and economic factors bring us a relative or absolute increase in happiness always has been of central importance in economically motivated happiness studies, both concerning the well-being of individuals (Oswald 1997; Frijters et al. 2004; Kahneman and Deaton 2010) as well as the well-being of whole nations (Easterlin 1974; Hagerty and Veenhoven 2003; Deaton 2008; Di Tella and MacCulloch 2008; Graham 2009). The results show that we observe consistently high and stable levels of happiness and satisfaction over the last decades, especially in Western countries. The Database of Happiness (Veenhoven 2020), for example, provides a comprehensive insight into happiness scores and correlates all around the world.

Johannes Klement

johanneskl@wupperinst.org

1 Wuppertal Institut, Döppersberg 19, D 42103 Wuppertal, Germany 


\subsection{Stabilisation of Happiness}

The question of how to stabilise life satisfaction is strongly related to the theory of adaptation (Brickman and Cambell 1971; Brickman et al. 1978; Lyubomirsky 2011). Happiness or life satisfaction in any form is a process of becoming and passing away. An adaptive process usually begins with a negative starting condition, a desire or a need for change. In aspiration of the change (Clark et al. 2008) or once a condition is reached which eliminates the starting condition, happiness changes and adaption begins: we slowly get accustomed to the change or satisfaction that comes from eliminating the desire or need (Frederick and Loewenstein 1999), whereas the fortunate effect lasts as long as we pay attention to it (Kahneman and Thaler 2006; Armenta 2014). After that, other desires come to the light, and the process begins again (Schopenhauer 1909, §58). Edgeworth (1881, 99-102) visualises the process appropriately by a seismograph recording a constant up and down from hedons (happiness particles), whereas today the metaphor of a hedonistic treadmill (Brickman and Cambell 1971) dominates. Locked in a treadmill, we try in vain to become permanently happier and fall back again and again to an initial level. Whereas the happiness-altering effect of an event will be adapted within a few months (Suh et al. 1996). Noted exceptions of the treadmill effects are negative life events that are related to the sense of life such as unemployment and widowhood, which are adapted over many years only or not even fully (Lucas et al. 2004; Clark et al. 2008). Also, the positive link between wealth and happiness at national and individual levels indicates that wealth does not fully adapt (Layard 2006) as it adds utility longterm (van Praag 1989; van Praag and Frijters 1999; Frey et al. 2004, cp.). On the one hand the rate of adaptation and the fortunate effect of changes are influenced by societal perceptions. Frederick and Loewenstein (1999) argue, that people tend to over exaggerate their happiness after positive events to be in line with societal expectations. On the other hand, genetic factors are shaping individual adaptation: By examining twins, Lykken and Tellegen (1996) argue that the falling back in the hedonic treadmill is genetically determined in such that they conclude: "It may be trying to be happier is as futile as trying to be taller [...]." However, other research shows, that on the question of life satisfaction the set point has turned out to be changeable in the course of life (Fujita and Diener 2005; Headey and Muffels 2016).

Various studies have shown that the genetic component accounts for a majority of the variation of happiness related aspects (Tellegen et al. 1988; Kendler et al. 1993; Lykken and Tellegen 1996; Nes et al. 2006), but there is still enough room to become the architect of one's own fortune. With regard to life satisfaction, as we examine below, it is known that, despite the high genetic character and the adaptation of life events, there is latitude (Diener et al. 2006; Diener 2014; Powdthavee and Stutzer 2014; Sheldon and Lucas 2014, e.g.) to wilfully exert a lasting influence on the overall satisfaction. Headey et al. (2010) conclude: "Contrary to the implications of set-point theory, it seems clear that human beings can escape the hedonic treadmill. Following lines of inquiry favoured by economists and positive psychologists, we have shown that life goals, religion, and personal choices matter for happiness."

Summarising the state of research, according to Lyubomirsky et al. (2005), three aspects of happiness and life satisfaction are decisive:

- Genetic determination

- Happiness-relevant circumstantial factors

- Happiness-relevant activities and practices 


\subsection{Survey Based Life Satisfaction}

One of the most frequently investigated concepts of subjective well-being in current specialist literature is the concept of life satisfaction (LS). Life satisfaction as a part of subjective well-being refers-in addition to emotional well-being - to the rational evaluation of life (Diener 1984, 2000; Kahneman and Deaton 2010). The rational components include the evaluation of our life, as well as satisfaction with individual domains such as work or family life. Although there is a distinction in theory, a rational evaluation of life is not possible without considering affective states in practice (Schwarz and Clore 1983; Schwarz 1987, cf.).

A large part of research on life satisfaction is based on the operationalisation of the concept due to surveys (Cantril 1966; OECD 2013). The life satisfaction question is also part of the German Socio-Economic Panel (Goebel et al. 2019), which provides the data for this article. At the end of a usually longer questionnaire on personal issues, life satisfaction is captured by means of the question- "How satisfied are you with your life in general?". Answers are given on an 11-step numerical scale, running between the two extremes very satisfied $(L S=10)$ and very dissatisfied $(L S=0)$. A precise definition is given in Sect. 3.1.

\subsection{Aim of Research}

In happiness research we commonly start with questions that focus on gaining and maintaining more happiness or less unhappiness. The question "How do we become happier?" is a key question of life for many people. In view of the already very high levels of happiness in many countries, the existence of adaptive processes that put a hamster wheel into perspective again and again as happiness gains, our unbiased initial question does not apply to more happiness, but to preservation: "How do we stay satisfied? How can we preserve our life satisfaction?" Hence our first research question is derived from.

Do the same happiness correlates that increase life satisfaction also increase the probability to stay satisfied on a certain level, or are there possibly other effects that decide about stabilisation?

At the same time, there is still a need for research into the cause of consistently high life satisfaction scores: "Explaining why some people persistently report very high levels of life satisfaction, or record big gains and somehow maintain them, is a harder task and one which deserves priority," (Headey and Muffels 2016, p. 34). Answers to that question also could be derived directly from the life satisfaction scale and presumably may allow to distinguish between the 'how' and the 'why' of stabilisation. Our second research question is:

Which method can we use-based on life satisfaction data collected on a 11-step numerical scale - to find connections between stability and changes in life satisfaction?

The choice of method for this research is based on the conviction that by using mathematical concepts and applying mathematical operations, statements about the stability of life satisfaction gain in reliability. Purpose of this article is thus to derive a methodological approach that can be used to determine the effect of happiness correlates on the stability of life satisfaction, based on the SOEP. Our method is based on a Negative Binomial Quasi Maximum Likelihood Estimator (NBQMLE). We use a strong definition of stability here, in such that we only consider the cases where respondents report the same life satisfaction scores for multiple years in a row. We contrast this with the results of a Fixed Effects 
Ordered Logit BUC estimate with which we determine the influence of happiness correlates on the growth of life satisfaction.

\section{Data and Literature}

\subsection{Data}

The SOEP is a longitudinal panel data set started in 1984 sampling households living in Federal Republic of Germany and re-interviewing them annually. Additional households are regularly added to replace dropped out households or to respond to changes in the demographics of Germany in order to keep the dataset representative. The dataset itself is published annually by the Deutsches Institut für Wirtschaftsforschung (German Institute of Economic Research) considering annual questionnaires by TNS Infratest Sozialforschung, a Munich based institute for research on public opinion. Under the name of "Leben in Deutschland-Living in Germany" individuals and households are interviewed on the basis of different questionnaires covering aspects of life of the participants (Goebel et al. 2019). Most notably, the Personal Questionnaire covers individual issues such as personal characteristics and opinions, financial and societal standing. The Household Questionnaire covers issues about family life. All data used in the following are based on these two questionnaires.

The SOEP dataset used here covers the annual waves from 1984 to 2013, including 62,579 different participants over this period, resulting in 498,061 observed person years.

\subsection{Literature Concerning Correlates of Life Satisfaction (Happiness Correlates)}

The term happiness correlates comprises behaviours and environmental factors that have been proven to affect well-being in a positive or negative way (Argyle 1999; Headey et al. 2010; Veenhoven 2020). The happiness correlates listed below are used in the following to verify the statistical method for the analysis of the stability of life satisfaction derived below.

One of the strongest correlations of life satisfaction - and vital to the standard of living - is the amount of the aggregate income of the household, in which the interviewed person lives (Frijters et al. 2004; Layard 2006; Frey and Frey Marti 2010), providing a stronger effect on life satisfaction than individual income. Rich people are not necessarily happier than poor, but the correlation between income and life satisfaction is generally positive (Biswas-Diener and Diener 2002; Kahneman and Deaton 2010), whereas long-term income shocks on the other hand lower life satisfaction (Bayer and Juessen 2015).

Social activities and exercise are central to various aspects of well-being. In this article we consider the number of hobbies someone regularly pursues, as well as voluntary work and regular exercise. Referring to the health definition of the World Health Organisation (WHO 1946) - Health is "a state of complete physical, mental and social well-being"-, these activities not only influence our mental and physical health but are also related to other aspects of our personal development and what we call life's meaning. Thus a broad literature confirms the positive influence of sport (Diener and Biswas-Diener 2008; Lee and Park 2010; Huang and Humphreys 2011) and voluntary work (Thoits and Hewitt 2001; Meier and Stutzer 2008; Headey et al. 2013) on life satisfaction. 
Social relationships, especially marriage, are among the most robust correlates of life satisfaction (Helliwell and Putnam 2012). Although married people are not necessarily happier than unmarried people, the relative happiness of a marriage depends strongly on the character traits of the partner. On average, married people are happier (Lykken 2000, p. 17), since life in a marriage strengthens different mental aspects of happiness (Orden and Bradburn 1968), especially those that play a role in coping with misfortune.

To have a paid job is regarded as particularly meaningful and central to the development of life satisfaction. Job loss leads to a sharp and lasting (Lucas et al. 2004) decline in life satisfaction, independent of the loss in income (Winkelmann and Winkelmann 1998; Oswald 1997).

Furthermore, the age of respondents is considered in the model, since there is a U-shaped relationship between age and life satisfaction. Life satisfaction generally declines until the midlife crisis, then rises again, and declines in old age (Gerstorf et al. 2010). Life satisfaction is lowest-depending on the underlying data set-somewhere between the end of the 30s and the beginning of the 50s (Oswald 1997; Blanchflower and Oswald 2008; Graham 2009; Dickerson et al. 2014).

In addition a seasonal dummy will be added accounting for winter mood. People who were interviewed during the winter months of January and February report significantly lower life satisfaction $(L S=6.88, N=168,594)$ than people who were interviewed between March and December $(L S=7.11, N=329,467)$. Life satisfaction includes information about seasons and weather (Schwarz and Clore 1983; Schwarz 1987, cp.).

\section{Methods}

\subsection{Capturing Life Satisfaction in the SOEP}

Life satisfaction is a concept, a measure that is determined empirically via surveys, using an integer scale. In the SOEP (Goebel et al. 2019), it is asked by means of an integral 11-step scale, running from 0 to 10 (Cantril 1966, p. 21 et sqq.). The scale is fanned out between the two extremes very dissatisfied (0) and very satisfied (10). The middle of the scale, the neutral point, is (5), indicating indifference between dis- and satisfaction. This classification allows to divide the scale into satisfied and dissatisfied states: The values 0-4 thus depict dissatisfied states, whereas 6-10 represent satisfied states. A more detailed discussion of applying such a scale can be found in the OECD Guidelines on Measuring Subjective Well-being (OECD 2013).

The according question in the SOEP-questionnaire is:

"In conclusion, we would like to ask you about your satisfaction with your life in general. Please answer on a scale from 0 to 10 , where 0 means completely dissatisfied and 10 means completely satisfied. How satisfied are you with your life, all things considered?

$\begin{array}{lrrrrrrrrrr}0 & 1 & 3 & 3 & 4 & 5 & 6 & 7 & 8 & 9 & 10 \\ \text { Completely dissatisfied } & & & & & & & \\ \text { Completely satisfied.” }\end{array}$

In a long series of questions (https://www.diw.de/en/diw_02.c.222729.en/questionnaires. html) on aspects of individual life, the question about life satisfaction is the final one. This is to ensure that the participants, after commenting on the most important aspects of their lives, provide a reasonably sound and hopefully only slightly distorted answer, to reduce the 
risk that people will respond from the gut, or be affected by external effects. Further item and scale statistics for the life satisfaction measurement in the SOEP are provided by Richter et al. (2017, pp. 20-33).

Despite the ordinal character of the Cantrill ladder, life satisfaction is usually treated as an interval variable. Both the assumption of ordinal or interval character of the scale lead to equivalent results for life satisfaction measurement (Andrews and Withey 1976, e.g.).

\subsection{Defining Life Satisfaction as a Variable}

The responses we receive when applying the Cantril ladder are defined as the realisations of a random variable $Y_{t}$ in year $t$, whereas $y_{t}$ denotes the realisation of $Y_{t}$ within a sample space $\Omega$, defined by the Cantril ladder, $y_{t} \in \Omega=\{0,1,2,3,4,5,6,7,8,9,10\}$. The realisations of a sequence of annual life satisfaction scores $Y_{t},\left\{Y_{t}, t=0,1,2, \ldots\right\}$, are a time discrete stochastic process with $Y_{t} \in S=\{0,1,2,3,4,5,6,7,8,9,10\}$.

\subsection{Counting for Stays in a Life Satisfaction State}

In the following, we will show that we can generally take a person's individual life satisfaction scores $y_{i, t}$ as independent observation points. Independent here means that past realisations $y_{i, t}, y_{i, t-1}, \ldots, y_{i, t-n}$ of $y_{i, t}$ have no influence on future life satisfaction scores. Exceptions could come from events, such as unemployment that leads to a lasting decline in life satisfaction (Lucas et al. 2004), that trigger long-standing adaptive processes. Such effects would show up as negative coefficients of lagged realisations of life satisfaction. But adaptive processes usually occur over the span of a few months (Suh et al. 1996). Thus, adaptive processes should not effect annual realisations of life satisfaction.

Bottan and Perez Truglia (2011) show that for life satisfaction in the SOEP the opposite is the case. As it is to be understood as a first-order autoregressive process, with the delayed effect being positive. This positive effect is most likely due to unobserved effects or the inconsistency of life satisfaction scores over time. Since life satisfaction is a latent variable, the individual definition of life satisfaction is most likely inconsistent over time as certain aspects of life satisfaction are weighted (configural invariance) or measured (measurement invariance) differently over time (Eid and Kutscher 2014).

Any first order autoregressive stochastic process is considered memoryless in terms of the Markov property. Thus the consideration of realisation of life satisfaction scores beyond the previous year, $y_{t-1}$, should not provide any additional information about the realisation of $y_{t}$ (see, for example, Anderson (1976)).

The definition of the Markov property for $Y_{t}$ is:

Definition 3.1 (Markov Property) A process $Y_{t}$ has the Markov property if $Y_{t+1}$ is conditional independent of the past realisations $Y_{0}, \ldots, Y_{t-1}$ given $Y_{t}$ :

$$
\begin{aligned}
& P\left(Y_{t+1}=b \mid Y_{t}=a, Y_{t-1}=a_{t-1}, \ldots, Y_{0}=a_{0}\right)=P\left(Y_{t+1}=b \mid Y_{t}=a\right) \\
& \forall t \geq 0, b, a, a_{t-1}, \ldots, a_{0} \in S .
\end{aligned}
$$




\subsection{Distribution of Time Constant Life Satisfaction States in the SOEP}

Treating individual realisations of life satisfaction in the SOEP as a Markov process, the probability $p_{a a}$ of in a state $a \in S$-thus the probability that someone reports the same life satisfaction score for consecutive years-is geometrically distributed, since the Geometric distribution is the only discrete distribution with the property of memorylessness. Hence, the stay in a state $a \in S$ can be grasped as a Bernoulli process (a repeated Bernoulli experiment), where $q=1-p$ is the average probability of a person in the sample being unsuccessful. That is, failing to stay in a state $a \in S$. The number of $k$ years (successes) a person remains in a state before she leaves (fail), follows the Geometric distribution. The average probability for repeating a life satisfaction score $k$ times, $P(X=k)$, is thus given as

$$
P(X=k)=(1-p)^{k} p \quad \text { for } k=0,1,2, \ldots
$$

The mean $E(X)$ and the variance $\operatorname{Var}(X)$ of the Geometric distribution are defined as

$$
E(X)=\frac{1-p}{p} \text { and } \operatorname{Var}(X)=\frac{1-p}{p^{2}} .
$$

By rearranging the failing probability $p$ is received:

$$
E(X)=\frac{1-p}{p} \Longrightarrow p=\frac{1}{1+E(X)}
$$
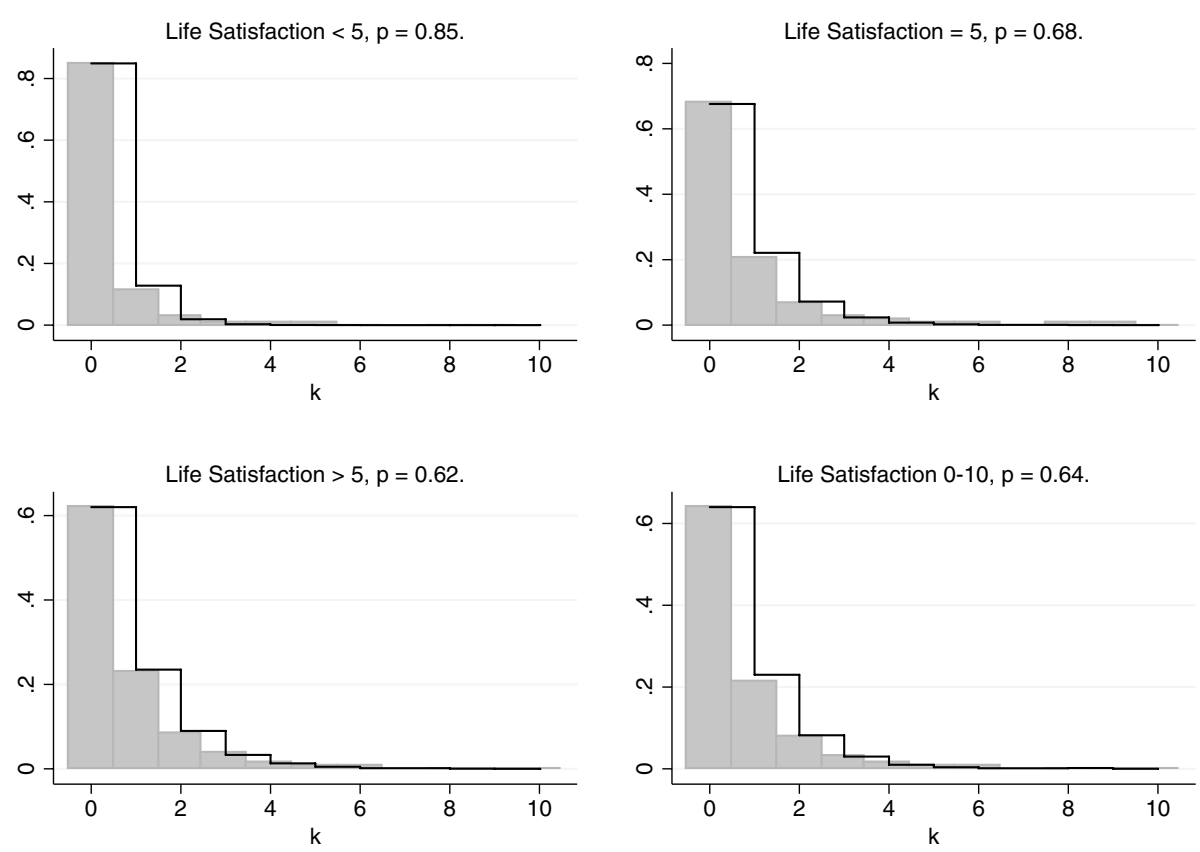

Fig. 1 Expected geometric versus SOEP-sample probabilities of $P(X=k)$. Geometric probabilities are represented by stairsteps, whereas sample probabilities are shown as bars 
Figure 1 shows the likelihood that a person in SOEP will stay $k$-times in the same state of life satisfaction. The actual sample probabilities are represented by lines, the bars indicate the probabilities of the Geometric distribution. $E(X)$ is used as the mean $\mu$ for the Geometric distribution. Figure 1 distinguishes between staying in a satisfied state $(N=200,672)$, in a dissatisfied state $(N=20,288)$, and the neutral state $(N=30,484)$. The last chart shows the probabilities of staying $k$-times in the same state in the whole sample $(N=251,444)$.

The graph shows that the participants repeat something rare their life satisfaction score, as it indicates the Geometric distribution. On the other hand, there are a few participants who repeat their life satisfaction more often than the geometric distribution indicates, but this is difficult to see from the graph due to the small number. It is also noticeable that the probability of repeating unsatisfied states is far lower than that of repeating satisfied states or the neutral state 5 .

\subsection{Econometric Approach}

Now we specify an estimation method which allows for determining the influence of external effects, $x$, on the likelihood of staying in a state. The dependent variable, the number of consecutive successful stays in a state $a \in S, k$, is count data. In the following and in line with standard notation, the dependent variable is denoted by $y$.

The comparison of the success rates in the sample with the geometric distribution show that the data deviates from the basic assumption, as individual probabilities vary over time, and the individual realisations also appear not to be independent. Likewise, unobserved effects and misspecification of a model presented in the latter, have a negative effect. As a consequence, the conditional variance $\operatorname{Var}(y \mid x)$ will be increased.

Concerning these aspects, in the following we will discuss the Poisson quasi-maximum likelihood estimation (PQMLE) also known as generalised linear model (GLM) with a log link based on (Cameron and Trivedi 1986, 2014) and (Wooldridge 1997, 2010). It is generally robust against misspecification such as lack of independence of individual observations and other individual heterogeneity (Ismail and Jemain 2007; Wooldridge 2010). The quasi-maximum likelihood method is basically equal to the maximum likelihood method. The prefix quasi indicates a possible misspecification of the underlying likelihood function.

\subsubsection{Quasi-Maximum Likelihood Estimation}

The central property of QMLE is the parity of conditional mean and conditional variance: $\operatorname{Var}(y \mid x)=E(y \mid x)$. In general this is not the case for most distributions obtained from data in the social sciences (Cameron and Trivedi 2014). Usually, the variance is greater than the mean, which is the case for $k=y$ here. Whereas the mean is around $0.5-0.8$, the variance is always larger (cf. Fig. 1). Therefore makes sense to calculate the conditional mean without having to make any statements about the conditional variance. Thus here the following link function is used:

$$
x_{i} \beta=\log \left(\mu_{i}\right),
$$

providing a logarithmic relationship between the linear predictor and the mean $\mu_{i}$ of the distribution function. The conditional mean function is received by solving Eq. 3.4 for $\mu_{i}$. It is thus defined by the exponential function 


$$
E\left(y \mid x_{i}\right)=\mu_{i}=e^{\left(x_{i} \beta\right)} .
$$

If the conditional mean deviates from the conditional variance (i.e. $\operatorname{Var}(y \mid x) \neq E(y \mid x)$ ), a one moment distribution will be biased. We thus need to use a two moment distribution relying on different variance and mean. Such a generalisation is provided by the Negative Binomial quasi-maximum likelihood estimator (NB2QMLE), which accounts for an overdispersion or heterogeneity parameter $\alpha$. The general notation for the Negative Binomial probability function (Cameron and Trivedi 1986) is

$$
f\left(y_{i} \mid \mu_{i}\right)=\frac{\Gamma\left(y_{i}+1 / \alpha\right)}{\Gamma\left(y_{i}+1\right) \Gamma(1 / \alpha)}\left(\frac{1}{1+\alpha \mu_{i}}\right)^{1 / \alpha}\left(\frac{\alpha \mu_{i}}{1+\alpha \mu_{i}}\right)^{y_{i}} .
$$

Taking the logarithm of Eq. 3.6 we get the quasi log-likelihood function $l_{i}$,

$$
\begin{aligned}
l_{i} & =-\frac{1}{\alpha} \log \left(1+\alpha \mu_{i}\right)-y_{i} \log \left(1+\alpha \mu_{i}\right)+y_{i} \log \left(\alpha \mu_{i}\right) \\
& =-\left(\frac{1}{\alpha}+y_{i}\right) \log \left(1+\alpha \mu_{i}\right)+y_{i} \log \left(\alpha \mu_{i}\right) .
\end{aligned}
$$

The nominal variance assumption for the NB2QMLE is

$$
v_{i}=\mu_{i}+\alpha \mu_{i}^{2}=e^{\left(x_{i} \beta\right)}\left(1+\alpha e^{\left(x_{i} \beta\right)}\right) .
$$

From the conditional mean function (Eq. 3.5) we can derive the coefficient $\beta$ for the QMLE family:

$$
\frac{\partial E(y \mid x)}{\partial x_{i}}=\partial e^{\left(x_{i} \beta\right)} \beta
$$

Solving for $\beta$ yields:

$$
\beta=\frac{\partial e^{\left(x_{i} \beta\right)} / \partial x_{i}}{\partial e^{\left(x_{i} \beta\right)}}=\frac{\partial E(y \mid x) / \partial x_{i}}{\partial E(y \mid x)}=\frac{\partial \log [E(y \mid x)]}{\partial x_{i}},
$$

whereas the chain rule was used in the last step.

$\beta$ can be interpreted as a semi-elasticity. The value of $\beta$ on $x_{i}$ indicates that a person with an additional unit in $x_{i}$ is expected to have $\beta$ percent more successes.

\subsubsection{Overdispersion}

In the case of economic and sociological data, the variability generally exceeds that of an underlying assumed distribution (Cameron and Trivedi 2014). This is also the case with regard to our data, as we show in Sect. 3.4. The assumption of a geometric distribution of staying in life satisfaction states is not entirely correct. This can be due to dependencies over time or varying success rates. Misspecification of a model to be estimated also lead to overdispersion.

The Geometric QMLE (NB1QMLE) results as a special case of the NB2QMLE. The fundamental Geometric regression model for an observation $i$ is thus obtained by Eq. 3.6, setting $\alpha=1$. Thus the Geometric QMLE 


$$
f\left(y_{i} \mid \mu_{i}\right)=\frac{\Gamma\left(y_{i}+1\right)}{\Gamma\left(y_{i}+1\right)}\left(\frac{1}{1+\mu_{i}}\right)\left(\frac{\mu_{i}}{1+\mu_{i}}\right)^{y_{i}} .
$$

The quasi log-likelihood function is

$$
l_{i}=-\left(1+y_{i}\right) \log \left(1+\mu_{i}\right)+y_{i} \log \left(\mu_{i}\right) .
$$

The mean is $\mu_{i}$ and the variance results from Eq. 3.8, setting $\alpha=1$ :

$$
v_{i}=\mu_{i}+1 \mu_{i}^{2}=\mu(1+\mu) .
$$

Since the overdispersion is presumably greater than one, however, we estimate a Two-step NBQMLE (Wooldridge 1997, p. 379), where in the first step we estimate $\alpha$ under the variance assumption (Eq. 3.8) and then the entire model.

As a result, we hope that the two-step NBQMLE solves the problem of increased variability and that the overdispersion is close to 1 . Here we determine post estimation the overdispersion based on McCullagh and Nelder (1989), introducing an overdispersion parameter $\sigma^{2}$, which is defined as the fraction of the variance and the variance function

$$
\sigma^{2}:=\frac{\operatorname{Var}\left(y_{i}\right)}{v_{i}}
$$

From post-estimation statistics $\sigma^{2}$ is calculated as

$$
\sigma^{2}=\frac{\text { Pearson' }^{\prime} X^{2}}{N-P} .
$$

Thus $\sigma^{2}$ is defined as the ratio of the Pearson goodness-of-fit statistic of the estimation and the number of observations $N$ minus the number of parameters $P$, i.e. the number of degrees of freedom of the model.

\subsubsection{Conditional Logistic BUC Estimator}

We further estimate a fixed effects ordered logit model with the same variables and choosing life satisfaction as the dependent variable, looking for the average absolute change in life satisfaction given the model. Here we choose the Blow-Up and Cluster (BUC) estimator developed by Baetschmann et al. (2011), which is among the most consistent and efficient estimators (Baetschmann et al. 2011; Riedl and Geishecker 2014), given the heterogeneity in the SOEP. Since the procedure has already been carried out several times with regard to life satisfaction data, it is not discussed here, but we refer to Baetschmann et al. (2011) and Riedl and Geishecker (2014). Regarding the output of the estimation, in the BUC procedure every observation is multiplied by a factor $K-1$, where $K$ is the total number of categories of the ordered categorical response variable. Thus the number of observations exceeds the sample size Tables 1 and 2 .

\subsection{Description of Variables}

The variable married was completed in comparison to the SOEP, in that missing values were counted as 1 (married), if the person was married in the past and following year, did not leave the household and the same was true for the spouse. 
Table 1 Content of the variables (also see Sect. 2.2)

\begin{tabular}{|c|c|}
\hline Variable & Description \\
\hline Life satisfaction & $\begin{array}{l}\text { Captures the individual answers to the life satisfaction question as described } \\
\text { in Sect. 3.1. Dependent variable, }\end{array}$ \\
\hline $\mathrm{k}$ & $\begin{array}{l}\text { Captures the number of years a person reports the same life satisfaction. Cf. } \\
\text { Sect. 3.4. Dependent variable; }\end{array}$ \\
\hline More than 2 hobbies & $\begin{array}{l}\text { Is } 1 \text { if the number of hobbies is above the average individual number of } \\
\text { hobbies in the sample-which is two-and } 0 \text { if the reported number of } \\
\text { hobbies is lees than two; }\end{array}$ \\
\hline Weekly exercise & Is 1 if the interviewed exercises at least once a week, 0 if less; \\
\hline Voluntary work & Is 1 if the interviewed is volunteering at least once a week, 0 if less; \\
\hline Married & $\begin{array}{l}\text { Takes the value of } 1 \text { if the person is married, } 0 \text { if divorced, single or wid- } \\
\text { owed; }\end{array}$ \\
\hline Unemployed & $\begin{array}{l}\text { Registers unemployment in such that it is } 1 \text { if the interviewed is officially } \\
\text { registered as job seeking and } 0 \text { otherwise; }\end{array}$ \\
\hline Log of real household income & $\begin{array}{l}\text { Is the logarithm of the annual real income }(2011=100) \text { of the household a } \\
\text { person lives in; }\end{array}$ \\
\hline Change in household income & $\begin{array}{l}\text { Denotes the change in real household income in } € 100,000 \text { compared } \\
\text { between two years; }\end{array}$ \\
\hline Age \& age ${ }^{2}$ & Control for age related effects; \\
\hline Dummy winter & $\begin{array}{l}\text { Takes the value } 1 \text { if the interview was performed in January and February } \\
\text { and } 0 \text { otherwise. It is used as a seasonal dummy to control for seasonal } \\
\text { effects. }\end{array}$ \\
\hline
\end{tabular}

Table 2 Summary statistics

\begin{tabular}{llllll}
\hline Variable & Min & Max & Mean & Std. Dev. & Frequency \\
\hline Life satisfaction & 0 & 10 & 7.04 & 1.8 & 510,179 \\
k & 0 & 20 & 0.63 & 1.2 & 424,572 \\
More than 2 hobbies & 0 & 1 & 0.29 & 0.45 & 484,446 \\
Weekly exercise & 0 & 1 & 0.39 & 0.49 & 319,607 \\
Voluntary work & 0 & 1 & 0.19 & 0.39 & 319,607 \\
Married & 0 & 1 & 0.62 & 0.48 & 479,348 \\
Unemployed & 0 & 1 & 0.08 & 0.27 & 500,505 \\
Dummy winter & 0 & 1 & 0.63 & 0.48 & 503,786 \\
Log of real household income & -4.49 & 10.32 & 5.8 & 0.6 & 505,934 \\
Change in household income & -2749827 & 1898241 & 760.3 & 15777.2 & 447,300 \\
Age & 18 & 103 & 46.2 & 17.1 & 510,179 \\
\hline
\end{tabular}

The income related variables are not transformed to binary variables as well as age and age $^{2}$. The variable change in household income is maybe the least relevant parameter in this model, but is included it since it still slightly contributes to the overall quality of the model. Short term changes in the variation of change in household income are not expected to have an effect on the change of life satisfaction, but the variable is used in our model to test for stability issues. 


\section{Results}

In correspondence to the Cantril ladder split discussed in Sect. 3.1, a model including the correlates described in Sect. 2.2 is estimated using both the BUC and NB2QML approaches. Firstly for all participants. i.e. the whole sample. Secondly differentiating between satisfied $(L S>5)$, indifferent $(L S=5)$ and dissatisfied $(L S<5)$ persons in the sample. For the BUC method, the estimation for indifferent states is omitted since a regression in one point is not possible.

As in Eq. 3.10 derived, the coefficient $\beta$ of the NB2QMLE is a semi-elasticity: The value of $\beta_{i}$ for the regressor $x_{i}$ indicates that an extra unit in $x_{i}$ is expected to increase chances to stay in a certain life satisfaction level by $\beta$ percent. For example, for the first NB2QML estimate in Table 3, married has a coefficient of 0.0305 . Thus a person, given the model, has $3.05 \%$ more successes in staying in a life satisfaction state on average when being married, compared to a person who is not married.

\subsection{Estimation Results}


Table 3 Estimation results

\begin{tabular}{|c|c|c|c|c|c|c|c|}
\hline \multirow{4}{*}{$\begin{array}{l}\text { Estimation } \\
\text { Independent variable }\end{array}$} & \multirow{2}{*}{\multicolumn{4}{|c|}{$\frac{\text { Negative binomial QMLE }}{\text { Number of successes }(\mathrm{k})}$}} & \multicolumn{3}{|c|}{ Conditional ML BUC } \\
\hline & & & & & \multicolumn{3}{|c|}{ Life satisfaction $(0,1, \ldots, 10)$} \\
\hline & LS & LS $>5$ & $\mathrm{LS}=5$ & $\mathrm{LS}<5$ & LS & $\mathrm{LS}>5$ & LS $<5$ \\
\hline & (1) & (2) & (3) & (4) & (5) & (6) & (7) \\
\hline More than 2 hobbies & .0688 & .0089 & .1001 & .0540 & .1117 & .0828 & .1492 \\
\hline$P>|z|$ & 0.000 & 0.000 & 0.000 & 0.205 & 0.000 & 0.007 & 0.000 \\
\hline Weekly exercise & .1614 & .1492 & -.0232 & -.1152 & .1785 & .1390 & .2409 \\
\hline$P>|z|$ & 0.000 & 0.000 & 0.394 & 0.022 & 0.000 & 0.000 & 0.000 \\
\hline Weekly voluntary work & .0891 & .0858 & -.0606 & .1158 & .0430 & .0179 & .1872 \\
\hline$P>|z|$ & 0.000 & 0.000 & 0.093 & 0.282 & 0.020 & 0.365 & 0.046 \\
\hline Married & .0305 & .0470 & -.0802 & -.1731 & .2076 & .1968 & .2203 \\
\hline$P>|z|$ & 0.000 & 0.000 & 0.000 & 0.002 & 0.000 & 0.033 & 0.000 \\
\hline Log of real household income & .2030 & .2204 & -.1707 & .0354 & .2336 & .1745 & .2146 \\
\hline$P>|z|$ & 0.000 & 0.000 & 0.000 & 0.238 & 0.000 & 0.001 & 0.000 \\
\hline Change in household income $\times 10^{-} 6$ & -1.71 & -1.940 & 2.220 & 2.11 & .3510 & -.7300 & 1.700 \\
\hline$P>|z|$ & 0.000 & 0.000 & 0.067 & 0.282 & 0.404 & 0.069 & 0.449 \\
\hline Unemployed & -.3193 & -.3285 & -.0381 & .0143 & -.8188 & -.4779 & -.5125 \\
\hline$P>|z|$ & 0.000 & 0.000 & 0.360 & 0.783 & 0.000 & 0.000 & 0.000 \\
\hline Age & .0295 & .0246 & .0678 & .0851 & -.0273 & -.0757 & .0733 \\
\hline$P>|z|$ & 0.000 & 0.000 & 0.000 & 0.000 & 0.000 & 0.000 & 0.000 \\
\hline $\mathrm{Age}^{2}$ & -.0002 & -.0002 & -.0006 & -.0007 & -.0002 & .0002 & -.0008 \\
\hline$P>|z|$ & 0.000 & 0.000 & 0.000 & 0.000 & 0.000 & 0.000 & 0.000 \\
\hline Dummy winter & .1180 & .1171 & .1711 & .1896 & -.0249 & -.0575 & .0443 \\
\hline$P>|z|$ & 0.000 & 0.000 & 0.000 & 0.000 & 0.048 & 0.000 & 0.408 \\
\hline Constant & -2.645 & -2.566 & -1.521 & -4.162 & & & \\
\hline$P>|z|$ & 0.000 & 0.000 & 0.000 & 0.000 & & & \\
\hline $\mathrm{N}$ & 245,482 & 195,307 & 30,484 & 29,887 & 805,998 & 379,320 & 24,162 \\
\hline$\alpha$ & 1.59 & 1.44 & 1.73 & 2.39 & & & \\
\hline$\sigma^{2}$ & 1.064 & 1.065 & 1.076 & 1.006 & & & \\
\hline Pseudo $R^{2}$ & & & & & 0.027 & 0.023 & 0.016 \\
\hline
\end{tabular}

\subsection{NB2QMLE Statistics}

The a priori estimated overdispersion parameters are listed as $\alpha$ in the lower part of Table 3 . The lowest value for $\alpha$ results from the estimation of satisfied states $(\alpha=1.44)$, the highest for dissatisfied states $(\alpha=2.39)$. Overall, overdispersion is close to 1 (geometric assumption). The values of $\sigma^{2}$ show that overdispersion could be remedied by the NB2QMLE according to McCullagh and Nelder (1989), since a value of $\sigma=1$ indicates the absence of overdispersion in the model post estimation. 


\subsection{Stabilising Effects on Life Satisfaction}

The first estimation provides the effect on the likelihood of remaining in a state based on the entire sample. With the exception of change in household income, unemployed, and age, all coefficients of the first estimate are positive. They thus show-in relation to the whole sample-an increased influence of the variables on the probability of remaining in a certain state.

Log of real household income has the highest coefficient in the model. A difference of 1 in logarithmic real household income, implies a 22 percent difference in the probability of a household member remaining in the same state. A change in income, however, has a destabilising effect in the short term, as the negative coefficient of change in household income shows.

The categorical variables more than 2 hobbies, weekly exercise and voluntary work indicate that healthy performance and social behaviour also contribute to a stabilisation of life satisfaction. Conversely, a lack of personal health care or poor access to social opportunities is destabilising life satisfaction.

People who exercise on a weekly basis are 16.14 percent more likely to report constant life satisfaction compared to those who are less active.

\subsection{Stabilisation of Satisfied States and Destabilisation of Dissatisfied States}

Estimations (2-4) allow for differentiation between the effects, the model's factors have on the likelihood of staying in satisfied $(L S>5)$, indifferent $(L S=5)$, and dissatisfied $(L S<5)$ states. The overwhelming majority $(195,307$ out of 245,482$)$ of all responses in the sample account for positive life satisfaction, not satisfied states account for only about 25 percent. Due to the high proportion of satisfied scores, the coefficients of Estimation (2) are approximately equal to the overall estimate (Estimation (1)).

In contrast to this, the results of the estimate for remaining in the satisfaction-neutral state ( $L S=5$, Estimation (3)) deviate significantly and show a reverse influence of the model. Except for more than two hobbies the coefficients are negative. Thus, they have a diminishing effect on the probability to stay in the neutral state.

The high p-values of the coefficients of the estimation for dissatisfied states $(L S<5$, Estimation (4)) suggest that in comparison our model may be suitable only to a very limited extent to describe stays in dissatisfied states. The reasons for this seem to lie in other factors, or possibly in the response behaviour, as people may constantly report negative life satisfaction regardless of external factors. Only married and weekly exercise show a statistical significant negative influence. This may be due to health problems or neglecting personal health care. Divorce or widowhood may be decisive for stabilisation in dissatisfied states. Surprisingly unemployment does contribute to stabilisation of dissatisfied states in our model. Although it is known that unemployment is not fully adapted and reduces life satisfaction in the long run (Clark et al. 2008), this effect does not seem to be reflected in an increased probability of remaining in an unsatisfied state.

\subsection{The Correlation Between Variability and Stabilisation in Life Satisfaction}

In the introduction we hypothesised a possibly positive correlation between the effects of the happiness correlates on staying in a state as well as on the variation of life 
satisfaction. The comparison of the NBQMLE and the BUC estimates should provide clarification.

The coefficients of the BUC estimates are consistently positive and significant. For both dissatisfied and satisfied states, the model has a positive effect on life satisfaction. Differences between the two estimates lie in the coefficients of more than 2 hobbies, weekly exercise, married, and weekly voluntary work, which are more pronounced in dissatisfied states. In dissatisfied states, health or social problems seem to have a greater impact on life satisfaction. The relatively high coefficient of unemployed $(-.818)$ in Estimation (5), in turn, suggests that unemployment may be accompanied by a direct transition from satisfied to dissatisfied states.

A direct comparison of the coefficients of both the NB2QMLE and BUC estimations is quantitatively not possible, but differences arise in the relative expression of the coefficients. For example, the coefficients for married and unemployed are much less important in the NB2QMLE. On average, married is a determinant for the variation in satisfaction. But it makes little difference in the probability of remaining in a state of life satisfaction if someone is married or single.

The relationship between growth and stability in life satisfaction is limited to the upper part of the scale.

\subsection{The Influence of Age and Season}

The seasonal effect is quite pronounced in all seven regressions. Respondents surveyed in January or February are not only relatively dissatisfied with their life, but also more likely to report constant scores of life satisfaction, whereas respondents surveyed at some point in-between March and December show a higher variability of life satisfaction. The control variable age is also positively related to the likelihood of staying in a state, as well as with decreasing satisfaction. In general it thus applies that the older a person, the higher the probability to stay in a state, and the higher the probability of individual dissatisfaction with life.

\section{Discussion}

The results of our NB2QML estimations confirm a stabilisation of individual life satisfaction. Happiness correlates for positive realisations of life satisfaction have a positive effect on the likelihood of staying in a satisfied state. The same applies to the likelihood of staying in the satisfaction-neutral state of the scale $(L S=5)$. This, in turn, cannot be justified in terms of mathematical inevitability, but rather indicates that people may follow a pattern regarding their response behaviour. As they might position themselves in the middle of the scale due to uncertainty or indifference. A response behaviour, which is known under the term of central tendency bias. Behavioural patterns are also plausible with regard to stabilisation in satisfied conditions. Even people who are constantly very satisfied will still choose a point where they still have room to move upwards.

The lack of statistically significance of the model for dissatisfied states $(L S<5)$ further indicates that stabilisation in presence of happiness correlates only takes place in states that are 'good' according to the theory of happiness correlates and are therefore desirable (Headey 2006; Headey et al. 2010, 2013, cf.). 
There is still need for research regarding the realisation of life satisfaction based on behavioural patterns due to response behaviour.

As discussed in Sect. 3.3, life satisfaction is a latent concept. And it thus can be assumed that the weight of individual happiness correlates changes over time and that changes in life may lead to changes in the individual concept of life satisfaction (configural invariance) (Eid and Kutscher 2014). Thus, people can either judge their lives according to the scale, or adjust the concept of their lives so that it corresponds to a certain evaluation: "What do I have to do this year to remain as satisfied with my life as I was last year?" However, the results of the BUC estimates for satisfied and dissatisfied states at least indicate that the weighting of the individual correlates remains relatively stable regardless of satisfaction.

The fact that stabilisation at the satisfaction-neutral point becomes more likely by reversing the model indicates two different facts. First, people do not adapt their concept of life to a changed life situation, but suffer from the fact that this concept is not realised. Furthermore, this reversal in the neutral state supports research that shows the possibility of a "long-term shift in life satisfaction states" (Headey et al. 2014). To the extent that people may or may not realise a relatively concrete concept of their lives. The stabilisation in both satisfied states and the neutral point given a similar concept of life satisfaction may be due to the fact that people fluctuate in their evaluation of their own life between two scenarios - a desirable and a non-desirable 'version' of their own life. Thus, people will possibly look for fixed points on the scale in which they stay in case of positive evaluation, or-if things go better or worse-deviate.

If research on stabilisation has so far focused on happiness correlates or personality traits, it obviously makes sense in view of the results to focus more on the effects that result directly from the scale as well as individual survey behaviour.

Funding Open Access funding enabled and organized by Projekt DEAL.

Open Access This article is licensed under a Creative Commons Attribution 4.0 International License, which permits use, sharing, adaptation, distribution and reproduction in any medium or format, as long as you give appropriate credit to the original author(s) and the source, provide a link to the Creative Commons licence, and indicate if changes were made. The images or other third party material in this article are included in the article's Creative Commons licence, unless indicated otherwise in a credit line to the material. If material is not included in the article's Creative Commons licence and your intended use is not permitted by statutory regulation or exceeds the permitted use, you will need to obtain permission directly from the copyright holder. To view a copy of this licence, visit http://creativecommons.org/licenses/by/4.0/.

\section{References}

Anderson, T. W. (1976). Panels and time series analysis: Markov chains and autoregressive processes. Tech. rep., Office of Naval Research \& Department of Statistics, Stanford University.

Andrews, F. M., \& Withey, S. B. (1976). Social indicators of well-being. Americans perceptions of life quality. New York: Plenum Press.

Argyle, M. (1999). Causes and correlates of happiness. In D. Kahneman \& N. S. Edward Diener (Eds.), Foundations of Hedonic psychology. New York: Russel Sage Foundation.

Armenta, C. (2014). Is lasting change possible? Lessons from the Hedonic adaptation prevention model. In Stability of happiness: Theories and evidence on whether happiness can change (pp. 57-74). Amsterdam: Elsevier.

Baetschmann, G., Staub, KE., Winkelmann, R. (2011). Consistent estimation of the fixed effects ordered logit model. Working Paper Series, Department of Economics, University of Zurich 4. 
Bayer, C., \& Juessen, F. (2015). Happiness and the persistence of income shocks. American Economic Journal: Macroeconomics, 7(2), 160-187.

Biswas-Diener, R., \& Diener, E. (2002). Will money increase subjective well-being? Social Indicators Research, 57, 119-169.

Blanchflower, D. G., \& Oswald, A. J. (2008). Is well-being U-shaped over the life cycle? Social Science and Medicine, 66(8), 1733-1749.

Bottan, N. L., \& Perez Truglia, R. (2011). Deconstructing the hedonic treadmill: Is happiness autoregressive? Journal of Socio-Economics, 40, 224-236.

Brickman, P., \& Cambell, D. (1971). Hedonic relativism and planning the good society. In M. H. Appley (Ed.), Adaptation-level theory (pp. 287-305). New York: Academic Press.

Brickman, P., Coates, D., \& Janoff-Bulman, R. (1978). Lottery winners and accident victims: Is happiness relative? Journal of Personality and Social Psychology, 36, 917-927.

Cameron, A. C., \& Trivedi, P. K. (1986). Econometric models based on count data: Comparisons and applications of some estimators and tests. Journal of Applied Econometrics, 1(1), 29-53.

Cameron, A. C., \& Trivedi, P. K. (2014). Count panel data. In B. Baltagi (Ed.), Oxford Handbook of Panel Data Econometrics (pp. 233-256). New York: Oxford University Press.

Cantril, H. (1966). The pattern of human concerns. New Brunswick: Rutgers University Press.

Clark, A. E., Diener, E., Georgellis, Y., \& Lucas, R. E. (2008). Lags and leads in life satisfaction: A test of the baseline hypothesis. The Economic Journal, 118(529), 222-243.

Deaton, A. (2008). Income, health, and well-being around the world: Evidence from the Gallup World Poll. The Journal of Economic Perspectives, 22, 53-71.

Di Tella, R., \& MacCulloch, R. (2008). Happiness adaptation to income beyond basic needs. Business, 44, 2003-2011.

Dickerson, A., Hole, A. R., \& Munford, L. A. (2014). The relationship between well-being and commuting revisited: Does the choice of methodology matter? Regional Science and Urban Economics, 49, 321-329.

Diener, E. (1984). Subjective well-being. Psycholigal Bulletin, 95(3), 542-575.

Diener, E. (2000). Subjective well-being. The science of happiness and a proposal for a national index. The American Psychologist, 55(1), 34-43.

Diener, E. (2014). Stable happiness dies in middle-age: A guide to future research. Stability of happiness: Theories and evidence on whether happiness can change (pp. 299-308). Amsterdam: Elsevier.

Diener, E., \& Biswas-Diener, R. (2008). Happiness: Unlocking the mysteries of psychological wealth. Malden: Blackwell Publishing.

Diener, E., Lucas, R. E., \& Scollon, C. N. (2006). Beyond the hedonic treadmill: Revising the adaptation theory of well-being. American Psychologist, 61(4), 305-314.

Easterlin, R. (1974). Does economic growth improve the human lot? Some empirical evidence. In David P, R. Melvin (Ed.) Nations and Households in economic growth: Essays in honor of moses Abramovitz, Academic Press.

Edgeworth, F. Y. (1881). Mathematical psychics. London: C. Kegan Paul.

Eid, M., \& Kutscher, T. (2014). Statistical models for analyzing stability and change in happiness. Amsterdam: Elsevier.

Frederick, S. W., \& Loewenstein, G. (1999). Hedonic Adaptation. In D. Kahneman \& N. S. Edward Diener (Eds.), Foundations of Hedonic psychology. New York: Russel Sage Foundation.

Frey, B. S., \& Frey Marti, C. (2010). Glück. Die Sicht der Ökonomie (German) [Happiness. The economic view]. Zurich: Rüegger Verlag.

Frey, BS., Luechinger, S., Stutzer, A. (2004). Valuing public goods: The life satisfaction approach. CESifo Working Paper Series 1158.

Frijters, P., Shields, M., \& Haisken-De New, J. P. (2004). Money does matter! Evidence from increasing real incomes in East Germany following reunification. American Economic Review, 94, 730-741.

Fujita, F., \& Diener, E. (2005). Life satisfaction set point: Stability and change. Journal of Personality and Social Psychology, 88(1), 158-164.

Gerstorf, D., Ram, N., Mayraz, G., Hidajat, M., Lindenberger, U., Wagner, G. G., \& Schupp, J. (2010). Latelife decline in well-being across adulthood in Germany, the United Kingdom, and the United States: Something is seriously wrong at the end of life. Psychology and Aging, 25(2), 477-485.

Goebel, J., Grabka, M. M., Liebig, S., Kroh, M., Richter, D., Schröder, C., \& Schupp, J. (2019). The German Socio-Economic Panel Study (SOEP). Jahrbücher für Nationalökonomie und Statistik / Journal of Economics and Statistics, 2(239), 345-360.

Graham, C. (2009). Happiness around the world. New York: Oxford University Press.

Hagerty, M. R., \& Veenhoven, R. (2003). Wealth and happiness revisited: Growing national income does go with greater happiness. Social Indicators Research, 64(1), 1-27. 
Headey, B. (2006). Life goals matter to happiness: A revision of set-point theory. DIW Discussion Papers 639.

Headey, B., \& Muffels, R. (2016). Towards a theory of life satisfaction: Accounting for stability, change and volatility in 25-year life trajectories in Germany. SOEP Papers, 864, 48.

Headey, B., Muffels, R., \& Wagner, G. G. (2010). Long-running german panel survey shows that personal and economic choices, not just genes, matter for happiness. Proceedings of the National Academy of Sciences of the United States of America, 107(42), 17922-17926.

Headey, B., Muffels, R., \& Wagner, G. G. (2013). Choices which change life satisfaction. Social Indicators Research, 112(3), 725-748.

Headey, B., Muffels, R., \& Wagner, G. G. (2014). National panel studies show substantial minorities recording long-term change in life satisfaction: Implications for set point theory. In K. Sheldon \& R. E. Lucas (Eds.), Stability of Happiness: Theories and Evidence on Whether Happiness Can Change (pp. 99-126). Amsterdam: Elsevier.

Helliwell, J. F., \& Putnam, R. D. (2012). The social context of well-being. The Science of Well-Being, 359(1449), 1435-1446.

Huang, H., \& Humphreys, B. R. (2011). Sports participation and happiness: Evidence from US micro data. New Horizons in the Economics of Sport, 33(4), 163-183.

Ismail, N., \& Jemain, A. A. (2007). Handling overdispersion with negative binomial and generalized poisson regression models. Casualty Actuarial Society Forum, Winter, 2007, 103-158.

Kahneman, D., \& Deaton, A. (2010). High income improves evaluation of life but not emotional wellbeing. Proceedings of the National Academy of Sciences of the United States of America, 107(38), 16489-16493.

Kahneman, D., \& Thaler, R. H. (2006). Utility maximization and experienced utility. Journal of Economic Perspectives, 20(1), 221-234.

Kendler, K., Neale, M., Kessler, R., Heath, A., \& Eaves, L. (1993). A twin study of recent life events and difficulties. Archives of General Psychiatry, 50, 789-796.

Layard, R. (2006). Happiness: Lessons from a new science. London: Penguin Books.

Lucas, R. E., Clark, A. E., Georgellis, Y., \& Diener, E. (2004). Unemployment alters the set point for life satisfaction. Psychological Science, 15(1), 8-13.

Lykken, D. (2000). Happiness: The nature and nurture of joy and contentment. New York: St. Martin's Press.

Lykken, D., \& Tellegen, A. (1996). Happiness is a stochastic phenomenon. Psychological Science, 7(3), $186-189$.

Lyubomirsky, S. (2011). Hedonic Adaptation to Positive and Negative Experiences. In S. Folkman \& P. Nathan (Eds.), The Oxford Handbook of Stress, Health and Coping (pp. 200-224). Oxford: Oxford University Press.

Lyubomirsky, S., Sheldon, K., \& Schkade, D. (2005). Pursuing happiness: The architecture of sustainable change. Review of General Psychology, 9(2).

McCullagh, P., \& Nelder, J. A. (1989). Generalized linear models. London: Chapman and Hall.

Meier, S., \& Stutzer, A. (2008). Is volunteering rewarding in itself? Economica, 75, 39-59.

Nes, R. B., Roysamb, E., Tambs, K., Harris, J. R., \& Reichborn-Kjennerud, T. (2006). Subjective wellbeing: Genetic and environmental contributions to stability and change. Psychological Medicine, $36(7), 1033-1042$.

OECD. (2013). Methodological considerations in the measurement of subjective well-being. $O E C D$ Guidelines on Measuring Subjective Well-being (pp. 61-138). Paris: OECD.

Orden, S. R., \& Bradburn, N. M. (1968). Dimensions of marriage happiness. American Journal of Sociology, 73(6), 715-731.

Oswald, A. J. (1997). Happiness and economic performance. The Economic Journal, 107(445), $1815-1831$.

Powdthavee, N., Stutzer, A. (2014). Economic approaches to understanding change in happiness. In: Stability of happiness: Theories and evidence on whether happiness can change, Elsevier, pp 219-244.

van Praag, BMS. (1989). The relativity of the welfare concept. World Institue for Development Economics Reasearch of the United Nations University working papers 69.

van Praag, B. M. S., \& Frijters, P. (1999). The measurement of welfare and well-being: The Leyden approach. In E. Diener, D. Kahneman, \& N. Schwarz (Eds.), Well-being: The foundations of hedonic psychology, January 1999 (pp. 413-433). New York: Russel Sage Foundation.

Richter, D., Rohrer, J., Metzing, M., Nestler, W., Weinhardt, M., Schupp, J. (2017). Soep scales manual (updated for soep-core v32.1). SOEP Survey Papers 423, DIW, Berlin.

Riedl, M., \& Geishecker, I. (2014). Keep it simple: Estimation strategies for ordered response models with fixed effects. Journal of Applied Statistics, 41(11), 2358-2374. 
Schopenhauer, A. (1909). The World As Will And Idea. Kegan Paul, Trench. London: Trübner \& Co.

Schwarz, N. (1987). Stimmung als Information. Untersuchungen zum Einfluß von Stimmungen auf die Bewertung des eigenen Lebens (German) [Mood as information. Studies on the influence of moods on the evaluation of one's own life]. Springer Verlag, Heidelberg.

Schwarz, N., \& Clore, G. L. (1983). Mood, misattribution, and judgments of well-being: Informative and directive functions of affective states. Journal of Personality and Social Psychology, 45(3), 513-523.

Sheldon, K., \& Lucas, R. (2014). The stability of happiness. Amsterdam: Elsevier.

Suh, E., Diener, E., \& Fujita, F. (1996). Events and subjective well-being: Only recent events matter. Journal of Personality and Social Psychology, 70(5), 1091-1102.

Tellegen, A., Lykken, D., Bouchard, T. J., Wilcox, K. J., Segal, N. L., \& Rich, S. (1988). Personality similarity in twins reared apart and together. Journal of Personality and Social Psychology, 54(6), 1031-1039.

Thoits, P. A., \& Hewitt, L. N. (2001). Volunteer work and well-being. Journal of Health and Social Behavior, 42(42), 115-131.

Veenhoven, R. (2020). Happiness in Nations. http://worlddatabaseofhappiness.eur.nl, accessed: 11/20/2020.

WHO. (1946). Constitution of the World Health Organisation. American Journal of Public Health, 36(11), $1315-1323$.

Winkelmann, L., \& Winkelmann, R. (1998). Why are the unemployed so unhappy? Evidence from Panel Data Economica, 65(257), 1-15.

Wooldridge, J. M. (1997). Quasi-likelihood methods for count data. In M. H. Pesaran \& P. Schmidt (Eds.), Handbook of applied econometrics II (pp. 352-406). Hoboken: Wiley-Blackwell.

Wooldridge, J. M. (2010). Econometric analysis of cross section and panel data. Cambridge, MA: MIT Press.

Lee, Young Hoon, \& Park, I. (2010). Happiness and physical activity in special populations: Evidence from Korean survey data. Journal of Sports Economics, 11(2), 136-156.

Publisher's Note Springer Nature remains neutral with regard to jurisdictional claims in published maps and institutional affiliations. 